\title{
Variação linguística na primeira pessoa do singular: o professor em formação na condição de sujeito
}

\author{
Marizete Bortolanza Spessatto ${ }^{1}$ \\ Luana de Gusmão Silveira ${ }^{2}$
}

\section{RESUMO}

Uma formação linguística democrática, assegurando a todos que passam pela escola o direito de reconhecer seus modos de falar como legítimos e o direito ao conhecimento das variedades consideradas de prestígio, demanda a intervenção dos professores de todas as áreas do conhecimento. Com essa premissa, este artigo visa contribuir com as discussões acerca das variações linguísticas presentes em sala de aula; analisar as diferentes ações dos professores diante delas e propor alternativas de trabalho nessa direção. Trata-se da análise de uma experiência desenvolvida junto a cursistas de pós-graduação, na qual as temáticas foram colocadas em discussão. Percebeu-se, com a análise dos dados, que: i) os professores reconhecem a diversidade linguística que chega à escola e as questões sociais às quais estão relacionadas; ii) tomam a escrita como referência para julgamento das variantes empregadas pelos estudantes na oralidade; iii) propõem estratégias de trabalho a serem aplicadas em sala de aula.

PALAVRAS-CHAVE: Variação linguística. Ensino. Formação de professores.

Language variation in the first singular person: the training teacher in subject condition

\footnotetext{
${ }^{1}$ Doutora em Educação. Instituto Federal de Educação, Ciência e Tecnologia de Santa Catarina, Florianópolis, Santa Catarina, Brasil. https://orcid.org/0000-0003-0213-833X. marizete.spessatto@ifsc.edu.br.

${ }^{2}$ Mestre em Linguística. Instituto Federal de Educação, Ciência e Tecnologia de Santa Catarina, Florianópolis, Santa Catarina, Brasil. https://orcid.org/0000-0003-2160-5327.luana.gusmao@ifsc.edu.br.
} 


\begin{abstract}
A democratic linguistic formation, assuring all students the right to recognize their speech varieties as legitimate and to access the considered prestigious varieties, demands the intervention of teachers from all knowledge fields. With this premise, this article aims to contribute to discussions about classroom linguistic variations; analyze different teachers' actions towards these variations and propose working alternatives. It's about analysis of an experiment developed with postgraduate students who discussed the above themes. The data analysis revealed that teachers: (i) recognize the classroom linguistic diversity and the social issues to which they are related; (ii) take writing as a reference for judging the students' oral variants; and (iii) propose classroom working strategies.
\end{abstract}

KEYWORDS: Classroom linguistic variation. Teaching. Teacher training.

Variación lingüistica singular en primera persona: el profesor en formación como individuo

\title{
RESUMEN
}

Una formación lingüística democráticas, que garantice a todos los que pasan por la escuela el derecho de tener reconocidas sus formas de hablar como legítimas y el derecho al conocimiento de las variedades prestigiosas, exige la intervención de profesores de todas las áreas del conocimiento. Con esta premisa, este artículo tiene como objetivo contribuir con el debate sobre las variaciones lingüísticas presentes en el aula; analizar las diferentes acciones de los docentes frente a ellas y proponer alternativas de trabajo en esta dirección. Se trata acerca del análisis de una experiencia desarrollada con estudiantes de posgrado, en la cual los temas fueron cuestionados. Con el análisis de los datos se observó que: i) los profesores reconocen la diversidad lingüística que llega a la escuela y los problemas sociales con los que están relacionados; ii) adoptan la escritura como referencia para juzgar las variantes empleadas por los estudiantes en el lenguaje oral; iii) proponen estrategias de trabajo para ser aplicadas en el aula. 
PALABRAS CLAVE: variación lingüística. Enseñanza. Formación de profesores.

\section{Introdução}

"Onde deixei meu penal ${ }^{3 "}$ ? A pergunta do aluno pegou a professora de surpresa. Ela até gostaria de ajudá-lo a procurar, mas, na verdade, a dificuldade em localizar o objeto partiu do desconhecimento do termo que o designa. A experiência faz parte da história de vida da professora T. T. ${ }^{4}$ (graduada em Administração de Empresas), uma paranaense que migrou recentemente para o norte de Santa Catarina. Como acontece com todos os brasileiros, basta mudar de região ou mesmo de estado, como é o caso aqui citado, para perceber que a afirmação de que no Brasil se fala uma "língua única" não passa de um mito (BAGNO, 2002, p. 51). T.T. integrou uma das turmas do curso de pós-graduação em Educação Profissional Integrada à Educação de Jovens e Adultos - PROEJA, ofertado por uma instituição da Rede de Educação Profissional e Tecnológica, no estado de Santa Catarina, no período de março de 2017 a setembro de $2018^{5}$. Como uma tarefa vinculada à disciplina de Letramentos, o grupo foi desafiado a escrever um texto no gênero editorial, a ser partilhado na ferramenta Fórum ${ }^{6}$. A

\footnotetext{
${ }^{3}$ Regionalismo do português brasileiro. "Estojo para guardar penas ou canetas, lápis, borracha e outro material semelhante", de acordo com Dicionário Priberam da Língua Portuguesa (2008-2013). Disponível em: https://www.priberam.pt/DLPO/penal. Acesso em 06 set. 2017.

${ }^{4}$ Os sujeitos cujos depoimentos são apresentados neste artigo são representados apenas pelas iniciais do nome e sobrenome (acrescidos da inicial de nome do meio, quando necessário para diferenciar os autores dos trechos, em caso de duplicidade de iniciais), a fim de preservar a identidade dos sujeitos. Também inserimos, entre parênteses, a área de formação inicial.

${ }^{5}$ Entre os critérios de seleção dos alunos, a maior pontuação, de acordo com o edital de ingresso, ficou com os profissionais atuantes na EJA e no Proeja, seguidos pelos profissionais da Educação de outras modalidades de ensino. Os sujeitos apenas graduados, sem experiência na área, tiveram uma pontuação baixa, o que fez com as turmas ficassem constituídas em grande parte por professores, seguidos por profissionais da área atuantes nas equipes de gestão ou no suporte educacional das escolas. (cf. critérios publicados no Edital de ingresso, disponível em: http://www.ifsc.edu.br/ead-editais/editais-ead-cfead. Acesso em 12 dez. 2017). Dados esses critérios, sempre que nos referirmos aos cursistas, usaremos o termo "professores em formação".

${ }^{6}$ A oferta acontece na modalidade Educação a Distância e a plataforma utilizada é o Moodle. De acordo com as orientações dessa plataforma, os fóruns são usados como estratégias para a efetividade da comunicação e construção de uma comunidade (cf. https://docs.moodle.org/all/pt_br/F\%C3\%B3runs. Acesso em 06 nov. 2019).
} 
produção deveria tratar da diversidade linguística característica da região em que cada cursista morava.

Ao realizar a atividade, o grupo foi levado a refletir sobre variação linguística não sob a perspectiva de um professor que identifica a presença desse fenômeno na fala dos seus alunos. Quando está nessa condição, via de regra, o docente adota o papel daquele que, popularmente falando, "tem o dever de corrigir". Com a proposta lançada, a intenção foi deixá-los no papel de sujeitos que identificam a presença de variação linguística na própria fala para, na sequência, refletir sobre esse fenômeno na fala de seus alunos de forma livre de preconceito. A decisão foi tomada levando-se em conta a assertiva de Bortoni-Ricardo (2004, p. 42): "[...] quando os modos de falar da criança [e, podemos acrescentar, de todos os estudantes] não são um campo de conflito, ela se torna mais aberta à aquisição de estilos mais monitorados". Esse movimento de reflexão sobre sua condição de falante (e de ouvinte) da língua portuguesa, com as muitas variações que a caracterizam, permite ao professor um repertório maior para lidar com a variação em sala de aula e com as crenças que os estudantes têm sobre elas:

Por exemplo, em um contexto de sala de aula em que os alunos afirmam (creem) que a língua portuguesa é "muito difícil" ou então que "falam mal" e "errado" a sua própria língua, se o professor propiciar a discussão sobre esse tema, considerando a variação linguística, essas crenças podem ser (re)significadas. (MARINE; BARBOSA, 2016, p. 195 - grifos no original).

A atividade desenvolvida também buscou ampliar as discussões sobre variação linguística com sujeitos advindos de distintos cursos de licenciatura e, muitos deles, já em exercício da docência em diferentes áreas do conhecimento, visando desconstruir a ideia de que a tarefa de tratar da formação linguística dos sujeitos que passam pela escola seja apenas do professor de português (FERRERI, 2010; NEVES et al, 2011). De acordo com Ferreri (2010, p. 21), para chegar a esse objetivo, é preciso integrar à 
formação de professores de todas as áreas "competências sobre linguagem e língua (de ordem teórica, sociolinguística, psicológica e histórica)”. Assim, assegurando a todos os alunos o acesso a uma educação linguística efetivamente democrática (FERRERI, 2010), de modo que seja a eles possibilitado "interagir socialmente em diferentes instâncias" (GÖRSKI; COELHO, 2009, p. 75).

As seções que compõem este artigo estão estruturadas a partir dos diferentes enfoques dados ao tema nos textos analisados, permitindo-nos refletir sobre: a concepção de variação linguística presente na fala dos professores em formação; as experiências docentes na condição de sujeitos falantes de diferentes variantes linguísticas ${ }^{7}$; as estratégias para o trabalho com a variação linguística em sala de aula. De modo geral, almeja-se contribuir com as discussões acerca das variações linguísticas que chegam à sala de aula; analisar as diferentes ações dos professores diante delas; propor caminhos para assegurar uma formação linguística efetivamente democrática, o que envolve o respeito à diversidade linguística e o direito de acesso às variantes de prestígio da língua a todos aqueles que passam pela escola.

\section{A concepção de variação linguística presente na fala dos professores em formação}

Colonizada por grupos étnicos diferentes, Santa Catarina também tem características linguísticas diversificadas. As três turmas que compuseram o curso aqui em análise ${ }^{8}$, cujas vozes dos professores em formação foram trazidas para este texto, caracterizam essa diversidade, estando localizadas: uma no sul do estado, uma no planalto e outra na região litorânea; logo, representam essa multiplicidade de falares.

\footnotetext{
${ }^{7}$ Empregamos o termo "variante linguística" considerando o que diz Labov $(1977,2008)$ para quem esse indica os modos alternativos de se dizer a mesma coisa. O conceito também é reforçado por Tarallo (1999) e Callou e Leite (2000).

${ }^{8}$ Essa composição de turmas em diferentes espaços geográficos foi possível, como já informado, pelo fato de a oferta do curso que reuniu esses sujeitos ter sido feita na modalidade a distância.
} 
Os textos deveriam ser escritos no gênero Editorial e publicados no Fórum da unidade curricular Letramentos, de modo a ser possível a visualização por todos os integrantes do curso. Considerando as ênfases dadas à escrita, respeitando o enunciado da tarefa, das 83 publicações feitas, apresentamos nesta seção as produções que, de algum modo, deixaram explícita a posição dos professores em formação acerca da variação linguística da sua comunidade ${ }^{9}$.

Mesmo que, como já indicado, a intenção da atividade tenha sido colocá-los na condição de usuários da língua e, por isso, como todos os falantes, detentores de variação linguística, em muitos depoimentos partilhados ficou evidente um olhar prévio de censura à variação. Ao apresentar a região em que reside, B.M. (graduada em Química) disse que: "Na região praiana de Santa Catarina, onde resido, leitor, há inúmeros vícios e variações de linguagem" (grifo nosso). Na sequência, ela apresenta expressões como "Segue reto toda vida" e "Está de bobiça?", comuns na região litorânea do estado, para exemplificar o que chamou de "vícios" e "variações". O uso da expressão "vício" pela professora em formação confirma o que tem se consolidado no senso comum, como aponta Bagno (2002, p. 50, grifos no original), ao afirmar que, via de regra, “[...] o que não está nas gramáticas não é norma culta: é 'erro crasso', é 'língua de índio', 'português estropiado' ou, simplesmente, 'não é português"'.

$\mathrm{O}$ estranhamento da professora em formação em relação às expressões por ela classificadas como vícios pode ser explicado pela condição social dos falantes, associada a nativos do litoral catarinense, a maioria deles ocupando funções como a de pescador. Em texto que traz à tona a discussão sobre os chamados "vícios de linguagem", Bagno (2002, p. 73) destaca a diferença de juízo de valor que um mesmo "erro" pode ter, dependendo de quem é o sujeito que o utiliza:

\footnotetext{
9 Em síntese, a proposta apresentada aos estudantes foi "Escrever um editorial para um jornal de sua cidade, refletindo sobre a variação linguística presente no contexto regional ao qual você pertence".
} 
[...] muitas vezes, um mesmo suposto erro é considerado como uma "licença poética" quando surge num texto assinado por um autor de renome ou na fala de um membro das classes privilegiadas, e como um "vício de linguagem" ou um "atentado contra a língua" quando se materializa na fala ou na escrita de uma pessoa estigmatizada socialmente. (BAGNO, 2002, p. 73).

Também aparece nos textos produzidos a relação entre a oralidade e a escrita, sobrepondo-se esta última como fator de orientação à primeira: "Sei que é uma questão de cultura e outros fatores, mas penso que seria de grande valia fazer um trabalho com alunos e mostrar como se escreve corretamente e tentar fazer com que falem da forma como se escreve, sem desrespeitar o contexto em que estão inseridos ou constrangê-los", afirma S.S (graduada em Pedagogia - grifos nossos). A professora A.L. (graduada em Ciências Biológicas) segue na mesma direção. Moradora de São José do Cerrito, descreve as variedades linguísticas presentes na escola e afirma que "os alunos trazem para sala de aula os sotaques que são acostumados a falar em sua casa. Então, nós, professores, temos que ensinar a eles o português formal que é utilizado na escrita" (grifo nosso). Bagno (2000, p. 50-74) caracteriza a afirmação "o certo é falar assim porque se escreve assim”, como um dos oito mitos do "círculo vicioso do preconceito linguístico". O autor destaca a histórica supervalorização da escrita sobre a fala e retoma Marcuschi (1998, p. 8 apud BAGNO, 2000, p. 79) para quem "o lugar mais evidente das crenças errôneas e equivocadas sobre a relação entre língua falada e língua escrita acha-se representado pelos manuais de ensino de língua".

Via de regra, afirma Marcuschi (1993), as gramáticas tratam as relações entre fala e escrita tendo como parâmetro esta última, gerando uma postura preconceituosa. Segundo Marcuschi (1993, p. 63), “os gramáticos imaginam a fala como o lugar do erro, incorrendo no equívoco de confundir a língua com a gramática normativa”. 
Görski e Coelho (2009, p. 74) destacam que as atividades didáticas que orientam o ensino de língua materna "[...] costumam ser basicamente classificatórias, desvinculadas do uso real da língua, regidas pelas noções de 'certo' e de 'errado', em que certo é o que está de acordo com as regras de tais gramáticas, ao passo que tudo o que não se conformar a essas regras é taxado de erro e deve ser corrigido". Dessa forma, tem-se, mais uma vez, a evidência de que a problemática da variação linguística e do próprio ensino de língua carece de uma discussão mais aprofundada nos cursos de formação inicial e continuada de professores.

Por um lado, se a primeira ação dos professores quando instigados a tratar sobre variação linguística é retomar preconceitos arraigados historicamente ao tema, por outro a produção aqui em análise mostrou a valorização dessa diversidade (possivelmente motivada pelas escolhas feitas pela maioria deles, que foi de apresentar a variedade lexical presente na língua portuguesa brasileira, mais do que os fenômenos de variação socialmente estigmatizados ${ }^{10}$ ). A associação entre variação linguística e diversidade cultural do país aparece de forma significativa nos textos analisados. "O Brasil é um país que, devido a sua colonização, há diferentes formas de se dizer a mesma coisa em diferentes cidades. [...] Há mistura, muitas vezes, das línguas [...] aqui é Brasil, país de cultura riquíssima e maravilhosa", diz a professora T.T., já apresentada na introdução deste texto. Ela cita, inclusive, a diversidade cultural da cidade em que vive que "por ter sido colonizada por várias etnias diferentes como a alemã, ucraniana, húngara, africana, polonesa e italiana, tem suas peculiaridades".

A diversidade lexical que constitui o português falado no país também é lembrada pela professora A. F. (graduada em Letras):

\footnotetext{
10 Em atividade de sala de aula, além do material de leitura disponibilizado no ambiente virtual de ensino aprendizagem, com reflexões conceituais, foi trabalhado com as turmas o capítulo 4, "A comunidade de fala brasileira", do livro Educação em Língua materna - a sociolinguística na sala de aula, de Stella Maris BortoniRicardo (2004, p. 45-50). No texto, a autora apresenta como fatores sociais que caracterizam a variação linguística presente em qualquer comunidade de fala: grupos etários, gênero, status socioeconômico, grau de escolarização, mercado de trabalho e rede social.
} 
Viajei sete anos pelo Brasil e pude perceber as diferenças e variedades de formas que podemos usar uma palavra, pois ela pode ter vários significados ou vários jeitos de falar a mesma coisa. Por exemplo em Lages, Santa Catarina, se eu falar: "pare quieto piá, se não vou te dar uma surra”, estou querendo dizer que darei uns tapas em um menino, mas já na região nordeste do país poderia dizer: "vou te dar uma pisa, menino" ou: "vou te dar uma peia, menino".

A professora A.W. (graduada em Pedagogia) associa variação linguística à diversidade cultural e sugere que nós, falantes e ouvintes da língua portuguesa brasileira, coloquemo-nos na condição de aprendizes, abertos à riqueza dessa diversidade: “[...] quanto às variações linguísticas, muitas vezes paramos para ouvir, apreciar e aprender sempre mais”. A análise desses fragmentos de produção dos professores nos permitiu uma sondagem inicial sobre a percepção dos educadores a respeito da variação linguística. Essas percepções serão ampliadas na sequência, quando partiremos para a análise dos depoimentos dos docentes quanto à variação presente na sua bagagem pessoal. Finalizamos esta seção com as palavras com as quais encerra o seu Editorial a professora S.O. "Acredito que diferenças existem não só na língua, mas em tudo e, por isso, devemos primeiramente respeitar e, se possível, procurar sempre conhecer, para depois tirar nossas conclusões". Poderíamos acrescentar: desempenhando, assim, a tão importante tarefa de contribuir com a formação linguística de todos que passam pela escola. 


\section{Os professores em formação na condição de sujeitos falantes de diferentes variedades linguísticas}

Ao olhar para uma comunidade linguística, percebe-se que ela não se caracteriza por uma única, mas por várias normas ${ }^{11}$. Elas também servem como fatores de identificação dos sujeitos, caracterizando os grupos sociais:

Como as normas são, em geral, fator de identificação do grupo, podemos afirmar que o senso de pertencimento inclui o uso das formas de falar características das práticas e expectativas linguísticas do grupo. Nesse sentido, uma norma, qualquer que seja, não pode ser compreendida apenas como um conjunto de formas linguísticas; ela é também (e principalmente) um agregado de valores socioculturais articulados com aquelas formas. (FARACO, 2008, p. 43).

É fundamental que todos os professores (reforçamos, mais uma vez, não apenas os de língua portuguesa), tenham consciência dessa diversidade, extremamente arraigada aos fatores sociais que caracterizam cada comunidade e fundamentais ao se pensar em uma formação linguística democrática na escola. Levados a refletir sobre o tema a partir de experiências pessoais, muitos dos sujeitos que compõem o corpus desta pesquisa retomaram episódios da infância relacionadas à variação linguística do seu grupo social. A professora C.G. se recorda de expressões de origem italiana presentes na fala em português, na comunicação cotidiana com os avós: "Na minha infância lembro de conviver com os nonos $^{12}$. [...] embora se comunicassem em português, sempre usavam

\footnotetext{
${ }^{11}$ Usaremos o conceito norma (que também poderia ser "norma culta", "português padrão" ou tantos outros termos) como o faz Faraco (2008). De acordo com o autor, o termo, nos estudos linguísticos, foi cunhado para captar a heterogeneidade constitutiva da língua. À perspectiva dicotômica sistema (social)/fala (individual), foi acrescido o termo norma: "Norma nesse sentido se identifica com normalidade, ou seja, com o que é corriqueiro, usual, habitual, recorrente (normal) numa certa comunidade de fala" (FARACO, 2008, p. 37).

${ }^{12}$ Do italiano i nonni (os avós). As palavras citadas na sequência, bella e cosa (bela e coisa) também são provenientes do italiano. Spessatto (2011) trata da presença de expressões do italiano na fala em português de descendentes de imigrantes hoje residentes em Santa Catarina.
} 
expressões como: 'grazie mille, néga' que significa 'muito obrigada' e 'néga' era a filha mais velha ou mais moça e qualquer mulher de quem não soubessem o nome que também poderia ser chamada de 'bella' ou 'cosa'”.

Outra experiência recuperada da infância é partilhada pela professora de Geografia S.W. Descendente de poloneses, entrou para a escola sem saber falar português. Dependia do irmão, que estava três anos à frente, para o processo de tradução. Ainda assim, descreve, "a professora tinha que ter uma ginga para trabalhar com isto tudo". Ao descrever as características da variedade falada em Lages, cidade onde reside, a professora S.A. descreve a variedade quase como uma "língua estrangeira": "Aqui [em Lages] a gente se entende, mas se cruzar as fronteiras, não dá muito certo, parece que estamos falando outra língua”.

Se não nas experiências familiares, quando levados a refletir sobre a variação linguística que os constituem, muitos professores retomaram a questão da diversidade étnica de Santa Catarina como um todo. "Para alguém que, como eu, vivi a maior parte da vida por aqui, fica difícil notar como falamos português", afirma o professor A.A., que reside em Criciúma há mais de trinta anos. O professor destaca como características mais marcantes da fala local a interferência de dialetos italianos na fala em português, levando à dificuldade "para pronunciar o ' $r$ ' duplo em palavras como 'carro', 'forro'. A pronúncia reproduzida acabava sendo 'caro', 'foro"'13.

O professor G.V. também retoma o processo de colonização, revelando a percepção sobre a diversificação cultural de uma cidade conhecida como ponto turístico pelas características italianas: Nova Veneza, no sul do estado. "Dentre as diferenças dos dialetos italianos no período da colonização, ainda possuía os povos nativos da região como os indígenas, formando-se assim, várias variações linguísticas e que segue se

\footnotetext{
13 De acordo com Spessatto (2011), a inexistência das geminadas, como exposto no depoimento, é uma das características que diferenciam, também na Itália, o dialeto vêneto - trazido pela maior parte dos imigrantes italianos vindos para o Sul do Brasil, do italiano oficial. Desta forma, afirma a autora, entre os imigrantes e seus descendentes, na fala em português, produz-se caro tanto para designar o preço de um eletrodoméstico quanto para referir-se ao veículo estacionado na garagem.
} 
transformando até os dias atuais, pois Nova Veneza possui em número expressivo de paranaenses, rio-grandenses, entre os Estados brasileiros".

A percepção da diversidade é ainda maior quando os sujeitos passam por movimentos de migração, deparando-se com novos modos de falar e "tendo de se adaptar a eles", como demonstram em muitos depoimentos. A professora S.C. conta que, assim que mudou para o sul de Santa Catarina, estranhava expressões usadas pelos alunos, mas também sentiu o estranhamento com o seu modo de falar, já que "[...] usava muitas expressões mineiras. Com o tempo fui me adaptando e hoje até me apropriei de algumas expressões catarinenses, e meus alunos já se acostumaram com o meu jeito de falar e as expressões que uso", afirma S.C.. "Quem migrou para o Estado de Santa Catarina há trinta e três anos, como eu, é muito interessante observar e adquirir familiaridade com a realidade linguística", conta V.E., hoje residente no litoral do estado. "Hoje, dizem que falo cantadinho, como catarina. E digo mais: como dengo-dengo (apelido dos habitantes de Navegantes)", complementa ela. "Eu sou nascido em São Paulo, mas morei por muitos anos em Blumenau e alguns em Itajaí também. Dizem que tenho sotaque mais parecido com alemães de Blumenau com algumas misturas", escreveu o professor L.F., residente em Balneário Camboriú. "Sou Natural de São Bento do Sul e lá em cima (Região Serrana) o jeito de falar difere-se do Vale do Itajaí Litoral Catarinense", descreve C.M. Os relatos fazem lembrar o conceito de estranhamento, cunhado por Coracini (2006). A autora descreve o que chama de mal-estar vinculado ao processo de adaptação a um novo local de moradia, gerado por aqueles que recebem os novos moradores sem que haja, efetivamente, um processo de acolhida.

A professora S.L.O. (graduada em Matemática) trata de forma descontraída a situação pela qual passou. Mudando de cidade, estado e até de país, ela avalia que "isso fez da minha própria variação linguística um desastre internacional”! Nascida no Espírito Santo e residente por dez anos na Espanha, ela vive no sul de Santa Catarina há nove anos e diz que levou 
um tempo para se adaptar com expressões usadas no solo catarinense, as quais ela considerava estranhas. "Essa foi a minha opinião sobre os 'catarinas', mas e o que eles acharam de mim? Nada bom. Foi horrível observar as pessoas rindo do que saía da minha boca, os comentários que só fazem graça àquele que se dispõe a falar. $\mathrm{O}$ respeitar e o aprender, o novo sempre traz receio e medo, mas podemos aceitar e aprender, eu aceitei e aprendi, hoje já sou quase catarina!", finaliza ela.

Mais do que a incorporação de uma variante linguística ao seu vernáculo, os professores deixam clara a noção de pertencimento ao local, a partir do momento em que fazem esse percurso linguístico. "Eu já nasci e fui criada no Rio Grande do Sul onde se pronuncia bá, tri, tri -legal, né. Tive um choque de variação linguística, mas hoje não falo mais como os gaúchos, me sinto uma catarinense litorânea, falando cantadinho igual ao povo de Itajaí”, relata F.S.. É um sentimento semelhante ao que se identifica na fala de S.A.O (graduada em Matemática):

Eu sou do estado do Paraná e quando cheguei em Lages percebi já de chegada que eles tinham uma variação linguística diferente da minha. Cheguei em Lages em 2002, desembarquei no bairro Coral e perguntei para um senhor onde passava o ônibus ele me respondeu: Ônibus só na rodoviária moça aqui passa a circular! Pensei: "circular" ... Foi bem diferente para mim escutar essas coisas. Hoje, com a convivência com meu marido que é nascido e foi criado e ainda permanece em Lages, já me acostumei e às vezes eu me pego falando essas expressões também.

Em pesquisa longitudinal, desenvolvida nos anos de 2008 e 2009, Spessatto (2011) identificou um sentimento parecido por parte dos estudantes. A comunidade em estudo na pesquisa é caracterizada pela interferência dos dialetos italianos na fala em português. Estudantes vindos de outras regiões do país ou até mesmo de outros municípios do estado 
demonstraram a tendência a buscar aproximar-se da variedade local, mesmo sendo ela socialmente estigmatizada:

Jaqueline: É, eles ficavam falando assim, né, porque eu falava torre [toRe] e aí eu ficava falando "ai, a 'tore' [tore] do meu celular não tá pegando". Aí eles ficavam imitando eu puxando os erres [eRes].

Entrevistadora: E hoje isso não acontece mais?

Jaqueline: Não. Ah, é porque eu já aprendi bastante. Já faz quatro anos que eu moro aqui então eu já aprendi quase tudo. (entrevista gravada em julho de 2008, SPESSATTO, 2011, p. 92).

Observamos, dessa forma, a tentativa de inserção social, manifestada pela apropriação de características linguísticas próprias da comunidade na qual buscam se inserir. Como falantes, ou seja, como sujeitos sociais, tanto alunos quanto professores almejam a aceitação do grupo do qual passam a fazer parte. Importante que os professores tenham isso em mente, quando estão diante de uma classe de alunos.

Quando reconhecidos como "estrangeiros", por conta da diversidade linguística que os constituem, os professores passam a entender a condição do aluno que chega à sala de aula dominando uma variante diferente daquela que é exigida pela escola. Com isso, fica mais clara também a leitura dos múltiplos falares que constituem o Brasil, como se evidencia na fala da professora S.W.: "Nessa breve contextualização podemos refletir que a diversidade étnica contribuiu para formar as diferentes variações linguísticas. Mesmo com políticas de governo para promover a homogeneização, muitas características sobreviveram e continuam resistindo à ideia de uma língua única”. Podem parecer questões simples, mas são preceitos importantes quando se trata da forma de ver e conduzir a formação linguística dos sujeitos que passam pela escola. São questões a serem ampliadas na próxima seção. 


\section{A variação linguística em sala de aula: o que pensam os professores em formação}

A problemática relação da escola com a questão da diversidade linguística resulta de diferentes fatores. Vem desde o modelo de ensino implementado historicamente no Brasil, inicialmente voltado apenas à elite (FARACO, 2008). Também passa pela dificuldade de as pesquisas linguísticas chegarem à escola (RAJAGOPALAN, 2003) e de o professor compreender seu papel diante da diversidade linguística (BAGNO, 2002; BORTONI-RICARDO, 2004; FARACO, 2008).

Para Faraco (2008), alterar esse quadro depende de uma mudança de atitude. O problema da diversidade linguística, para o autor, é bem maior do que "a regência desse ou daquele verbo", questão que normalmente aparece em debates públicos que fazem críticas aos modos de falar dos sujeitos menos escolarizados. A norma culta, na função que lhe atribui a sociedade urbanizada e massificada, está diretamente ligada com a escolarização, o letramento e a superação do analfabetismo funcional. O autor cita três metas que devem ser alcançadas para o avanço em relação ao acesso à norma culta como um bem cultural. A primeira delas é a universalização da educação básica, assegurando acesso a todos de 11 a 12 anos de escolarização. A segunda meta é oferta de educação de qualidade para todos, garantindo o domínio das práticas de leitura e escrita. A terceira é uma mudança na maneira de encarar a realidade linguística, respeitando as diferenças entre a fala e a escrita. À lista elaborada por Faraco (2008), podemos acrescentar uma quarta meta: a formação continuada de professores, de modo que as discussões sejam ampliadas, atualizadas e ressignificadas, como modestamente feito no trabalho desenvolvido com os professores em formação, na experiência aqui relatada.

Antes que se concretize a educação das crianças e dos jovens, é imprescindível que haja investimentos na área de formação de professores. Sabe-se que há um avanço muito significativo no que concerne às concepções 
e proposições teóricas ligadas à educação e ao processo de ensino aprendizagem, porém, os resultados de aplicações práticas com envolvimento e consequências para os professores em atividade ainda não são tão visíveis. Ainda no que diz respeito à formação continuada de profissionais, é importante destacar que a preocupação com os processos formativos de educadores e, consequentemente, com a articulação entre sua formação inicial e continuada, nos últimos anos, de acordo com Gatti (2008, p. 62), "entrou na pauta mundial", tendo em vista as "pressões do mundo do trabalho, que vêm se estruturando em novas condições, num modelo informatizado e com o valor adquirido pelo conhecimento", bem como pelo "precário desempenho escolar" dos educandos da Rede Básica de Ensino, desencadeando uma preocupação para a estruturação das "políticas públicas na direção de reformas curriculares".

Os sujeitos ouvidos para este trabalho, como de um modo geral apontam as pesquisas sobre o tema, também revelam uma preocupação com ensinar os alunos a "falarem da forma como se escreve" (professora S.S.). A professora V.V. (graduada em Letras) traz para o debate a preocupação com o que ela classifica como manifestações da variação na oralidade, presentes na escrita dos alunos:

Observo nos textos dos meus alunos um problema na escrita no caso das palavras 'ombro' e 'peito'. Os mesmos escrevem 'ombru' e 'peitu'. Esse fenômeno é conhecido como 'marcas da oralidade'. Ressalto para eles que dentro da norma culta há uma forma mais privilegiada de se falar. Esclareço que dependendo do contexto, podem até falar dessa forma, mas escrever, jamais. (professora V.V.).

O ensino prescritivo da língua, aponta a professora G.S., faz com que as diferentes variantes dessa língua se tornem mais visíveis, "[...] colocando para o aluno que tudo que é falado ou escrito fora da norma culta está 'errado', esquecendo que a língua é viva”. A percepção desse fato, entretanto, 
faz com que a professora apresente uma recomendação: "Claro que a gramática tem o seu valor e deve ser mantida, porém as variações linguísticas existem e elas devem ser trabalhadas em sala de aula." (professora G.S.). Ainda, as escritas sobre o tema variação linguística no curso aqui em análise trouxeram dos próprios professores em formação contra-argumentos e sugestões de trabalho com o tema, como o faz a professora J.T (graduada em Letras):

A escola tem um papel muito fundamental nesta formação da língua, pois tem por obrigação passar também a norma culta para seus alunos, mas não impondo sua ditadura perfeita no modo de falar! Pois a variedade linguística se dá na fala e não na escrita. Temos, sim, que expor sempre que pudermos a forma culta, mas, jamais deixar de lado a cultura do indivíduo, pois o mesmo já vem com seu jeito de falar no meio familiar onde é inserido!

Bortoni-Ricardo (2006b) afirma que uma formação sociolinguística permitiria ao professor (de todas as áreas do conhecimento, reforçamos) perceber a diferença existente entre um problema de ortografia e uma variação presente na oralidade, muitas vezes tratadas da mesma maneira pela escola. A autora reforça que é papel da educação formal ajudar os alunos a refletirem sobre a língua materna, em graus diferentes de abstração, de acordo com cada período da vida escolar:

Essa reflexão torna mais fácil para eles desenvolver sua competência e ampliar o número e a natureza das tarefas comunicativas que já são capazes de realizar, primeiramente na língua oral e, depois, também, por meio da língua escrita. A reflexão sobre a língua que usam torna-se especialmente crucial quando nossos alunos começam a conviver com a modalidade escrita da língua. (BORTONI-RICARDO, 2006b, p. 268). 
A autora considera a necessidade de distinção em relação às modalidades oral e escrita da língua, ao se tratar de variação linguística, questão pouco clara para muitos dos professores cujas vozes foram trazidas para este trabalho. As duas modalidades, segundo ela, diferenciam-se pelo chamado "estatuto do erro" (BORTONI-RICARDO, 2006b, p. 272). As variantes linguísticas caracterizam-se como diferenças entre possibilidades competitivas de dizer a mesma coisa: "A transgressão é, como já dissemos, um fato social, pois o estigma se lhe advém pela simples ruptura com uma etiqueta linguística”, reforça a autora (BORTONI-RICARDO, 2006b, p. 273). Por outro lado, em relação à variação presente na escrita, a autora aponta que representa "a transgressão de um código convencionado e prescrito pela ortografia".

Por ter a escrita tomada como modelo de "boa língua" também para a oralidade, a escola, por muito tempo ${ }^{14}$, desconsiderou ou tratou como erros as variedades pertencentes aos domínios linguísticos dos estudantes, especialmente aqueles das classes sociais mais baixas. Para Bortoni-Ricardo (2006a), no caso brasileiro, o ensino das variedades de prestígio aos sujeitos falantes das variedades populares da língua se dá de forma desastrosa. Em primeiro lugar porque não são respeitados os antecedentes culturais e linguísticos dos educandos. E, em segundo, porque a própria língua-padrão, como indica a autora em citação apresentada no início deste capítulo e que retomamos aqui, não é ensinada de forma eficiente:

Os alunos que chegam à escola falando "nós cheguemu", "abrido" e "ele drome", por exemplo, têm que ser respeitados e ver valorizadas as suas peculiaridades linguístico-culturais, mas têm o direito inalienável de aprender as variantes do prestígio dessas expressões. Não se lhes pode negar esse conhecimento, sob pena de

\footnotetext{
${ }^{14}$ Situamos essa perspectiva como fora do contexto atual do ensino de língua materna, porque assim o fazem os documentos oficiais que orientam o ensino. Porém, é preciso sempre, lamentavelmente, deixar uma ressalva a algumas práticas que, infelizmente, ainda permanecem presentes.
} 
se fecharem para eles as portas, já estreitas, da ascensão social. (BORTONI-RICARDO, 2006a, p. 15).

A preocupação em tratar a variação linguística de modo articulado com as questões sociais que levam a essa variação aparece no depoimento da professora R.B (graduada em Pedagogia). Ao apresentar as características que marcam a variação presente na região em que mora, caracterizada pela produção de tepe em contextos de vibrante múltipla (fenômeno já discutido ao longo deste texto), ela faz as seguintes proposições: "Cabe ao professor, em sala de aula, observar e avaliar quando o aluno está usando um dialeto local e quando realmente está ocorrendo um erro fonético, para que possa auxiliá-lo" (professora R.B.).

Para Faraco (2008), o papel da escola na formação linguística de seus alunos é o de sensibilizar em relação à variação:

O tema é rico para aprofundarmos nossa busca de alternativas pedagógicas que permitam pôr a escola na vanguarda, sensibilizando as crianças e os jovens para a variação e para seus sentidos sociais e culturais; contribuindo para uma reconstrução do nosso imaginário nacional sobre a nossa realidade linguística e, acima de tudo, combatendo a violência simbólica que ainda atravessa nossas relações sociais. (FARACO, 2008, p. 184).

Razões que nada têm de linguísticas atribuem valores diferentes às diferentes variedades da língua. Por isso, afirma Bagno (2002), é preciso deixar claro que:

O "erro" linguístico, do ponto de vista sociológico e antropológico, se baseia, portanto, numa avaliação negativa que nada tem de linguística: é uma avaliação estritamente baseada no valor social atribuído ao falante, em seu poder aquisitivo, em seu grau de escolarização, em sua renda mensal, em sua origem geográfica, 
nos postos de comando que lhe são permitidos ou proibidos, na cor de sua pele, em seu sexo e outros critérios e preconceitos estritamente socioeconômicos e culturais. (BAGNO, 2002, p. $73-$ grifo no original).

Quando o diálogo é aberto e os professores expõem suas preocupações sobre a presença da variação linguística em sala de aula, trazem à tona muitas formas de diversidade. É o caso exposto pela professora S.C.O. (graduada em Pedagogia), que atua como intérprete de Libras em uma escola pública no litoral catarinense. Essa atuação faz com que a professora perceba as variações existentes tanto na língua portuguesa quanto em Libras, o que, segundo ela,

[...] deveria ser trabalhado de forma mais saudável e que desse significado na vida dos mesmos [os alunos]. Na Libras também não é diferente, porque em cada região existe um sinal, às vezes diferenciado para uma palavra, por exemplo, aqui em Santa Catarina a cor verde é feito um 'v' e em movimento circular no dorso da mão, já em Curitiba é feito diferente, o movimento é no queixo. Isso também muitas vezes acaba confundido os surdos. Mas são as variações que devemos conhecer para saber de que forma mostrar ao nosso aluno tais variações e trabalhá-las também.

A professora D.S. (graduada em Pedagogia), paranaense que mora há 15 anos no litoral catarinense, também partilha da defesa de que todas as variedades linguísticas sejam respeitadas na escola. "Todos são bem-aceitos; é uma miscigenação de culturas e informações. Tanto os alunos como os professores já estão acostumados com esta variação linguística que faz parte do nosso cotidiano; é uma troca de informações que amplia nossos saberes culturais”, afirma ela. O mesmo se dá com a professora R.F. (graduada em Educação Física). A gaúcha que hoje reside no litoral de Santa Catarina 
recupera as memórias das experiências na nova terra com um episódio ocorrido no início do seu primeiro ano letivo na nova escola em que passou a atuar como docente.

O sinal já soou, os professores já circulam com seus alunos; motivados para iniciarem sua aula. Tudo indo bem, quando um aluno murmura: "Profe, o Augusto tomou meu penal é não quer me entregar". A reação foi imediata: o coleguinha retruca, "mentira, profe, di já hoje, este tanso mentiu de mim". [...] Estou aprendendo todo dia com os alunos e com a minha nova casa, a final "Bruxque" tem muito para me ensinar e a escola é um lugar ideal para este aprendizado linguístico.

O professor J.M. (graduado em Letras) aponta sugestões para o trabalho com a variação linguística em sala de aula em um contexto específico, o da Educação de Jovens e Adultos. Entre elas, a escrita coletiva de um livro da turma:

Cada aluno vai ao quadro e escreve uma frase ou um parágrafo da história da turma, pode ser uma apresentação ou contar os motivos porque está estudando na EJA. Ao escreverem ou narrarem para o professor escrever (de preferência), todos vão lendo e visualizando a decodificação da escrita correta, ou adaptações da palavra na variação linguística para a norma culta. Esse exercício pode funcionar de diversas formas, na aula regular no Google Drive como uma narrativa online colaborativa. Cada aluno contribui com sua escrita com uma cor diferente... assim o professor pode identificar e enviar nos comentários sugestões "da própria turma" de como ficaria melhor tal sentença emitida pelo colega.

A proposta feita leva em conta a preocupação de que o professor, como mediador do processo de escrita e, em consequência, de ampliação do 
vocabulário, assegure a compreensão dos fenômenos de variação que marcam o vernáculo dos alunos-escritores. É preciso, destaca ele, que os alunos percebam "como se transcreve a sua escrita repleta de variações, e que o identifica como falante da sua comunidade, ou grupo cultural à norma culta dos espaços letrados: livros, revistas, jornais, e principalmente a produção dos textos escolares" (professor J.M.).

A professora M.S. (graduada em Artes Visuais) também traz sugestões metodológicas para a EJA, partindo da diversidade linguística presente em sala de aula, em diferentes contextos: “[...] é possível inserir outros termos ou palavras utilizadas de forma diferente da formal e realizar com os alunos a confecção de um dicionário novo com essas variações e provocar assim o entendimento de outras maneiras de expressão a fim de melhorar a comunicação na vida social e do trabalho.”

Percebe-se, com os exemplos aqui apresentados, que os professores de diferentes áreas do conhecimento, quando instigados a refletir sobre variação linguística e ensino, não apenas ressignificam seus conceitos como apresentam propostas de trabalho com o tema. Dessa forma, corroborando com a proposta aqui defendida de que a educação linguística efetivamente democrática passa pela formação continuada na qual os professores partilham o protagonismo, sobretudo via a socialização de práticas exitosas.

\section{Considerações finais}

Este trabalho teve como pretensão refletir, a partir da partilha de uma experiência em curso de formação de professores em nível de pósgraduação, acerca do papel da escola diante da variação linguística presente na fala dos alunos que a ela chegam. No caso aqui em análise, os docentes foram colocados na condição de sujeitos e, então, instigados a pensar na variação linguística não na condição de quem é "autoridade, com o papel de corrigir”. A partir daí, como vimos, vários aspectos vieram à tona. 
Quando refletem acerca das suas trajetórias de vida, os professores em formação percebem o quanto questões de ordem social interferem nos domínios linguísticos. As experiências partilhadas revelam a compreensão desses profissionais de que variação linguística também constitui a identidade dos falantes, como descreve a professora S.P. (graduada em Letras): "[...] minha história que começou com um potiguar e uma barriga verde construindo uma família na terra da garoa. Eu mesma reformulei essa história ao me associar com um caipira e parir recentemente uma pexêra 15 ". Diante do questionamento da família acerca de "deixar a filha falar desse jeito", a professora, como conta em seu texto, asseverou: "Logo eu que percebo nessa língua tanta identidade e história e que reconheço a minha própria nela. Rapidamente me ponho a responder: tax tola, nega? E encerro qualquer bobiça" (professora S.P.).

Diante de posicionamentos como esse e das proposições feitas pelos próprios professores e socializadas no fórum do curso em questão e, também, neste trabalho, reforçamos o quanto é necessário investir na formação de professores. Como defende Spessatto (2011, p. 201):

É fundamental que as universidades e os cursos de formação continuada retomem a questão da variação linguística no aspecto crucial: o respeito à diversidade deve ser o ponto de partida, levando os estudantes a compreenderem os fatores sociais, históricos e políticos que a constituem. Urge que os conhecimentos científicos produzidos a respeito das questões linguísticas cheguem às escolas e contribuam efetivamente para mudanças na prática cotidiana com a linguagem em sala de aula.

Seguindo as narrativas estabelecidas pelos professores em formação, percorremos diferentes modos de pensar sobre os diferentes falares do estado de Santa Catarina (uma pequena amostra da diversidade linguística

15 "Pexêro/a" ou "manezinho/a" são adjetivos atribuídos aos sujeitos nascidos no litoral de Santa Catarina. Expressões presentes em diferentes redes sociais. 
deste país). Finalizamos reforçando a importância dessas reflexões com docentes de todas as áreas do conhecimento e de todos os níveis de escolarização. Afinal, o respeito à diversidade e uma formação de qualidade são direitos de todos.

\section{Referências}

BAGNO, Marcos. Dramática da língua portuguesa: tradição gramatical, mídia \& exclusão social. São Paulo: Loyola, 2000.

BAGNO, Marcos. A inevitável travessia: da prescrição gramatical à educação lingüística. In.: BAGNO, Marcos; STUBBS, Michael; GILLES, Gagné. Língua materna: letramento, variação \& ensino. São Paulo: Parábola, 2002.

BAGNO, Marcos; STUBBS, Michael; GILLES, Gagné. Língua materna: letramento, variação \& ensino. São Paulo: Parábola, 2002.

BORTONI-RICARDO, Stella Maris. Educação em língua materna, a sociolingüística na sala de aula. São Paulo: Parábola, 2004.

BORTONI-RICARDO, Stella Maris. Nós cheguemu na escola, e agora? Sociolingüística e educação. $2^{a}$ ed. São Paulo: Parábola, 2006a.

BORTONI-RICARDO, Stella Maris. O estatuto do erro na língua oral e na língua escrita. In.: GORSKI, Edair Maria e COELHO, Izete Lehmkuhl (orgs.) Sociolingüística e Ensino - contribuições para a formação do professor de língua. Florianópolis: Editora da UFSC, 2006b.

CALLOU, Dinah; LEITE, Yonne. Iniciação à Fonética e à Fonologia. Rio de Janeiro: Jorge Zahar, 2000.

CORACINI, Maria José. A celebração do outro: arquivo, memória e identidade línguas (materna e estrangeira), plurilinguismo e tradução. Campinas: Mercado de Letras, 2006.

GATTI, Bernardete A. Análise das políticas públicas para formação continuada no Brasil, na última década. Revista Brasileira de Educação v. 13 n. 37 jan./abr. 2008. Disponível em: http://www.scielo.br/pdf/rbedu/v13n37/06.pdf. Acesso em 18 nov. 2019.

GORSKI, Edair Maria e COELHO, Izete Lehmkuhl. Variação linguística e ensino de gramática. I. Revista Work. Pap. Linguist., 10 (1): 73-91, Florianópolis, jan. Jun., 2009 .

FERRERI, Silvana (a cura di). Dieci tesi per l'educazione linguistica democrática. Viterbo: Sette Città, 2010.

LABOV, William. Padrões Sociolinguísticos. São Paulo: Parábola, 2008 [1972]. 
MARINE, Talita de Cássia; BARBOSA, Juliana Bertucci. Em busca de um ensino sociolinguístico de Língua Portuguesa no Brasil. SIGNUM: Estud. Ling., Londrina, n. 19/1, p. 185-215, jun. 2016. Disponível em: http://www.uel.br/revistas/uel/index.php/signum/article/view/23161. Acesso em 15 dez. 2017.

NEVES, Iara et. al. (Org.). Ler e escrever: compromisso de todas as áreas. 9 ed. Porto Alegre: UFRGS, 2011.

RAJAGOPALAN, Kanavillil. O conceito de identidade em linguística: é chegada a hora para uma reconsideração radical? In.: SIGNORINI, Ines (org). Língua (gem) $e$ identidade: elementos para uma discussão no campo aplicado. Campinas: Mercado de Letras; São Paulo: Fapesp, 1998.

SIGNORINI, Ines (org). Língua (gem) e identidade: elementos para uma discussão no campo aplicado. Campinas: Mercado de Letras; São Paulo: Fapesp, 1998.

SPESSATTO, Marizete Bortolanza. Variação linguística e ensino: por uma educação linguística democrática. Florianópolis, SC, 2011. 237 p. Tese (Doutorado) - Universidade Federal de Santa Catarina, Centro de Ciências da Educação, Programa de Pós-Graduação em Educação, Florianópolis, 2011. Disponível em: $<$ http://www.bu.ufsc.br/. Acesso em 06 nov. 2019.

TARALLO, Fernando. A pesquisa sociolinguística. São Paulo: Ática, 1999.

Recebido em novembro de 2019.

Aprovado em janeiro de 2020. 